\title{
Mixing of a Hydrogen Jet from a Wedge Shaped Injector into a Supersonic Cross Flow*
}

\author{
By Fuminori SaKima, ${ }^{1)}$ Takakage ARAI ${ }^{2)}$ Jiro KaSAhara, ${ }^{2)}$ Masaya Murakoshi, ${ }^{1)}$ \\ Takayuki AmI, ${ }^{1)}$ Fei HE ${ }^{1)}$ and Hiromu SugIYAmA ${ }^{2)}$ \\ ${ }^{1)}$ Graduate School of Muroran Institute of Technology, Muroran, Japan \\ ${ }^{2)}$ Department of Mechanical Systems Engineering, Muroran Institute of Technology, Muroran, Japan
}

(Received December 18th, 2002)

\begin{abstract}
A new measurement by using a catalytic reaction on a platinum wire was conducted spatially to evaluate a mixing condition in a supersonic flow field. A spatial mixing field was created by a transverse hydrogen jet injected into a cold supersonic cross flow (Mach 1.81) through a wedge shaped injector. The half-vertical angles of $8^{\circ}$ or $18^{\circ}$ were chosen as that of the wedge shaped injector. These results were compared with that of a circular injector case. The results showed that this method could evaluate a spatial mixing condition. The results also clarified that a jet plume in the cases of wedge injectors penetrated higher than that of the circular injector case and separate from the lower wall when going downstream. To observe jet/supersonic flow interaction, Schlieren visualization and oil flow visualization were carried out. It was shown that the extent of the separation region around the $8^{\circ}$ wedge injector was the smallest among those injectors. Pitot pressure measurements were also conducted. These indicated that a wedge injector scheme was more beneficial than that of a circular injector for the supersonic combustion and combustor wall cooling.
\end{abstract}

Key Words: Supersonic Mixing, Jet/Supersonic Flow Interaction, Wedge Shaped Injector, SCRAM Jet Engine, Catalytic Reaction

\section{Nomenclature}

$C$ : coefficient of heat transfer

$\dot{m}$ : mass flow rate

$P$ : supplied electric power to thin wire

$Q$ : heat release (loss)

$R$ : radius

$T$ : temperature

$u$ : velocity

$x$ : streamwise direction

$y$ : spanwise direction

$z:$ vertical direction

$\rho$ : density

$\Delta P$ : difference between drift of electric powers to platinum wire and nickel wire because of difference of resistance in electric circuit

Subscripts

1: heat radiation

2: heat convection

b: effective radius

$\mathrm{g}$ : gas of freestream

$\mathrm{j}:$ jet

Ni: nickel

Pt: platinum

tc: heat conduction

w: mean temperature of wall

$\infty$ : freestream

(C) 2004 The Japan Society for Aeronautical and Space Sciences *Presented at the 43rd Conference on Aerospace Propulsion, Tokyo, January 31,2003

\section{Introduction}

The SCRAM jet engine is a candidate for the propulsion system of space transportation or hypersonic vehicles in the future. ${ }^{1)}$ If it is to become a reality, however some problems must be solved. One of its characteristics is that the freestream remains supersonic in the combustor. Specifically, the order of the residence time in the combustor is a millisecond. Therefore, the mixing between fuel jets and the freestream must be quick. Furthermore, the interaction between the boundary layer on the combustor wall and the jet must be considered, as this causes an excessive thermal loading on the wall. As a result, it will have negative effects on the wall cooling of the SCRAM jet engine combustor.

To address these issues, some injection schemes have been developed or suggested. ${ }^{2-9)}$ For example, a ramp injector is one of the schemes to enhance mixing by using induced vorticity. ${ }^{2-4)}$ An inclined injection scheme was suggested to reduce the total pressure loss of the freestream. ${ }^{5,6}$ ) Meanwhile, a wedge shaped injector ${ }^{7-9)}$ was developed to minimize both total pressure loss and jet-boundary layer interaction. Regarding investigations about wedge injectors, as far as we know, gaseous hydrogen has not been used as the injectant in the previous studies.

In order to develop these injection schemes, it is important to evaluate the mixing condition in the SCRAM jet engine. We have developed a new mixing condition evaluation method as described in our previous papers. ${ }^{4,6,10-15)}$ It was conducted by using a catalytic reaction on a platinum wire. In the previous studies, it was used to quantitatively inves- 


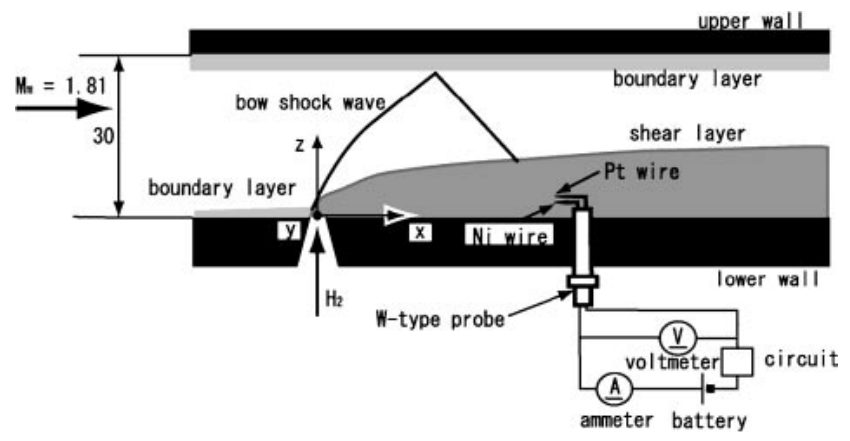

Fig. 1. Schematic of flow field.

tigate the mixing condition of a two-dimensional hydrogenair supersonic mixing layer. ${ }^{13,14)}$ We demonstrated that our technique applied to hydrogen concentration measurement was a useful and easy way to evaluate the mixing condition between the supersonic freestream and the hydrogen jet. We were unable to conduct a three-dimensional investigation, however, because of the size of the platinum wire probe.

In the present study, a spatial investigation was conducted by downsizing the platinum wire probe. Specifically, a transverse sonic jet was injected into a supersonic cross flow through a wedge shaped injector, which had a half-vertical angle of $8^{\circ}$ or $18^{\circ}$ (hereinafter an $8^{\circ}$ wedge or an $18^{\circ}$ wedge, respectively). The mixing condition was investigated by using a catalytic reaction on a platinum wire. In order to observe the jet/supersonic flow interaction, Schlieren visualization and oil flow visualization were carried out. In addition, in order to measure the total pressure loss, Pitot pressure measurements were also conducted. Meanwhile, we also conducted an investigation in a circular injector case and the results were compared with wedge shaped injector cases.

\section{Experimental Apparatus and Method}

\subsection{Experimental apparatus}

The suction type supersonic wind tunnel was used in the present study. The cross section of the test section was $30 \mathrm{~mm} \times 30 \mathrm{~mm}$. Figure 1 shows the flow field schematic. The coming freestream Mach number was about 1.81. In an isentropic condition, the static temperature in the test section would be about $180 \mathrm{~K}$. The gaseous hydrogen was injected normally into the freestream from one of the three injectors as shown in Fig. 2. These injectors had almost identical cross sectional areas of $7.0 \pm 0.1 \mathrm{~mm}^{2}$. These injectors were installed at the middle of the lower wall. The injector exchange was carried out by replacing the part of the lower wall. The jet-to-freestream momentum flux ratio was $J \approx$ 1.0 in all of these cases.

In order to investigate the behavior of the supersonic mixing layer and jet/freestream interaction, nanopulse (the exposure time was about $\left.30 \times 10^{-9} \mathrm{sec}\right)^{16)}$ Schlieren photographs were taken. An oil flow visualization (using a silicone oil whose dynamic viscosity was $3.0 \times 10^{-3} \mathrm{~m}^{2} / \mathrm{s}$ with a fluorescent pigment) was also conducted. In addition, Pitot

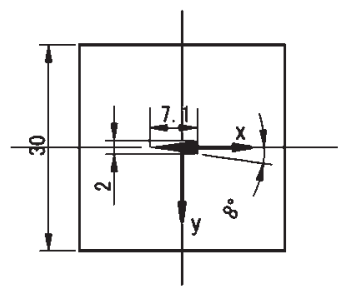

(a) $8^{\circ}$ wedge injector

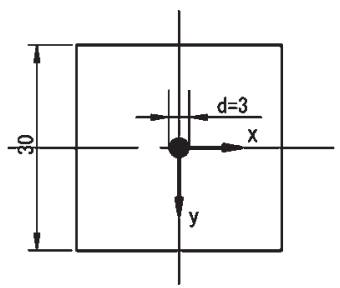

(c) Circular injector

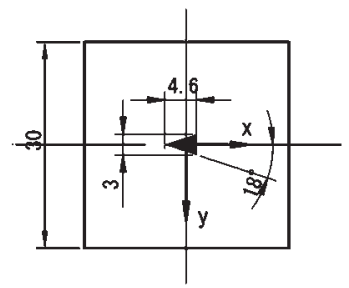

(b) $18^{\circ}$ wedge injector
Fig. 2. Schematic of injectors.

pressure was measured. A Pitot probe was installed into the flow field at $x=29,64$ and $99 \mathrm{~mm}$ locations, where $x$ was the streamwise distance from the centroid of the injector. The probe can go to the $z$ direction.

The probe, which measured the mixing condition between the supersonic freestream and the hydrogen jet, is also shown as a W-type probe in Fig. 1. This probe had both thin platinum and nickel wires (reference wire) and these wires were $1.4 \mathrm{~mm}$ long and $0.025 \mathrm{~mm}$ in diameter. Both wires were connected to each circuit for keeping constant temperature. However, in the present study, measurements were not conducted simultaneously in platinum wire and nickel wire cases.

In the hydrogen-air supersonic mixing layer, there was an electrically heated platinum wire, on which catalytic reaction occurred. The catalytic heat release rate was measured by adapting the technique of constant temperature type hotwire anemometers. The probe was installed into the flow field in the same way as the Pitot pressure measurements.

\subsection{Heat release due to catalytic reaction}

The energy balance on a thin wire in the flow field is given as follows;

$$
Q+P=C_{1}\left(T^{4}-T_{\mathrm{w}}{ }^{4}\right)+C_{2}\left(T-T_{\mathrm{g}}\right)+Q_{\mathrm{tc}}
$$

Where,

$Q(\mathrm{~W})$ : heat release due to catalytic reaction

$P(\mathrm{~W})$ : supplied electric power to a thin wire

$T(\mathrm{~K})$ : mean temperature of a thin wire

$T_{\mathrm{w}}(\mathrm{K})$ : mean temperature of wall

$T_{\mathrm{g}}(\mathrm{K})$ : temperature of freestream

$C_{1}\left(\mathrm{~W} / \mathrm{K}^{4}\right)$ : coefficient in Eq. (1) (heat radiation)

$C_{2}(\mathrm{~W} / \mathrm{K})$ : coefficient in Eq. (1) (heat convection)

$Q_{\mathrm{tc}}(\mathrm{W})$ : heat loss due to heat conduction

If a thin nickel wire is used, there are no cases where heat release occurs due to the catalytic reaction, (regardless whether it is in the mixing layer or out) so that $Q$ is neglected. Hence, Eq. (1) yields

$$
P_{\mathrm{Ni}}=C_{1}\left(T_{\mathrm{Ni}}{ }^{4}-T_{\mathrm{w}}{ }^{4}\right)+C_{2}\left(T_{\mathrm{Ni}}-T_{\mathrm{g}}\right)+Q_{\mathrm{tc}}
$$


In the case of using a platinum wire, $Q$ is not neglected in the mixing layer region because there is the possibility of heat release due to the catalytic reaction. Then, Eq. (1) yields

$$
Q+P_{\mathrm{Pt}}=C_{1}\left(T_{\mathrm{Pt}}{ }^{4}-T_{\mathrm{w}}{ }^{4}\right)+C_{2}\left(T_{\mathrm{Pt}}-T_{\mathrm{g}}\right)+Q_{\mathrm{tc}}
$$

On the other hand, there is no heat release due to the catalytic reaction out of the mixing layer region. Therefore,

$$
P_{\mathrm{Pt}, \text { out }}=C_{1}\left(T_{\mathrm{Pt}}{ }^{4}-T_{\mathrm{w}}{ }^{4}\right)+C_{2}\left(T_{\mathrm{Pt}}-T_{\mathrm{g}}\right)+Q_{\mathrm{tc}}
$$

In the present study, there is a difference between temperatures of Pt and Ni wires because of constant resistance in the electric circuit. As a result, there is a difference between supplied electric power to $\mathrm{Pt}$ and Ni wires out of the mixing region. This difference is because there is the temperature difference of wires (see Fig. 7). Equations (2) and (4) were combined to give this difference shown in Eq. (5).

$$
\begin{aligned}
\Delta P & =P_{\mathrm{Ni}, \text { out }}-P_{\mathrm{Pt}, \text { out }} \\
& =C_{1}\left(T_{\mathrm{Ni}}{ }^{4}-T_{\mathrm{Pt}}{ }^{4}\right)+C_{2}\left(T_{\mathrm{Ni}}-T_{\mathrm{Pt}}\right)
\end{aligned}
$$

Finally, under the above electric circuit conditions, the heat release due to catalytic reaction in the mixing layer is as follows;

$$
P_{\mathrm{Ni}}-P_{\mathrm{Pt}}=Q+\Delta P
$$

\section{Results and Discussion}

\subsection{Flow visualizations}

Figure 3 shows the typical results of the flow field observed by the Schlieren method. The flow direction was from left to right. Figures 3(a), (b) and (c) were taken in an $8^{\circ}$ wedge, $18^{\circ}$ wedge and circular injector cases, respectively. In Fig. 3, a bow shock wave was seen in all cases. In
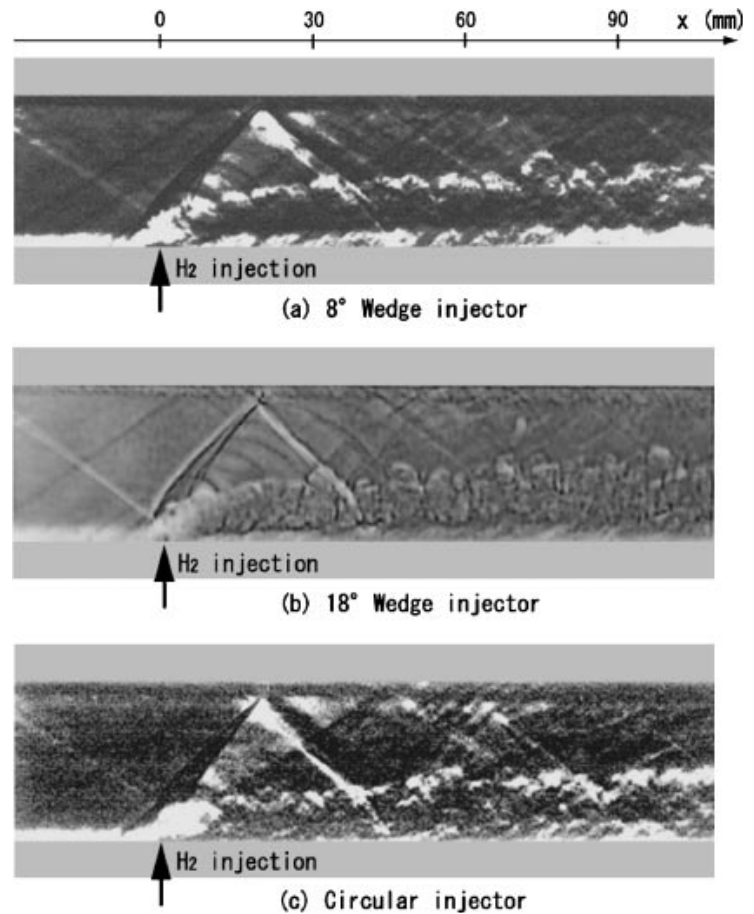

Fig. 3. Schlieren photographs of flow field.
Figs. 3(a) and (b), no separation shock wave was able to be seen just upstream of the $8^{\circ}$ wedge injector. On the other hand, in Fig. 3(c), a separation shock wave was apparently generated upstream of the injector. When comparing these mixing layers with each other, the penetrations of the mixing layer in the wedge injector cases seem to be higher than that of the circular injector case. A detailed comparison of the penetration height in these cases will be described later.

Figure 4 shows the typical results of the flow field observed from the oil flow visualization. The flow direction was from left to right. Figures 4(a), (b) and (c) show the typical results of the $8^{\circ}$ wedge, $18^{\circ}$ wedge and circular injector cases, respectively. In Fig. 4(a), no separation region upstream of the leading edge of the $8^{\circ}$ wedge injector was able to be seen. This was consistent with the result of Fig. 3(a). In Fig. 4(b), it was unclear whether there was a separation region upstream of the leading edge of the $18^{\circ}$ wedge injector. In Fig. 4(c), a separation region was seen upstream of the circular injector. The separation region was generated from about two diameters upstream of the leading edge of the circular injector on the $x$-axis (the centerline of streamwise). The trace-like parabolic line was seen from about one diameter upstream of the leading edge of the injector on the $x$-axis in Fig. 4(c). This may indicate that the separation region or the behavior of the re-circulation region in the boundary layer was changed. When comparing Figs. 4(a)-(c), the extent of the separation region around the injector was in the circular injector case larger than those in the wedge injector cases (obviously, the $8^{\circ}$ wedge injector case was smaller than the $18^{\circ}$ wedge case). From the trailing edge, counter waves just like an expansion fan were seen in Figs. 4(a) and (b). On the other hand, the wake from the trailing edge seems to be clearer in the circular injector case (Fig. 4(c)) than those in the wedge injector cases. It may imply that there was a smaller recirculation region downstream of the injector in the wedge shaped injector cases (Figs. 4(a) and

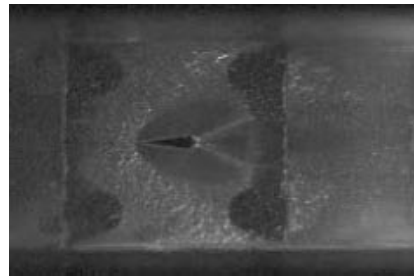

(a) $8^{\circ}$ wedge injector

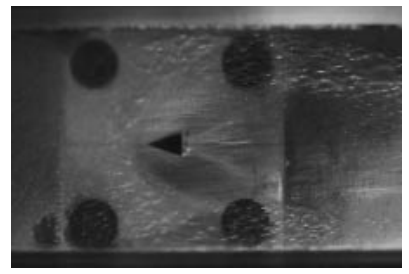

(b) $18^{\circ}$ wedge injector

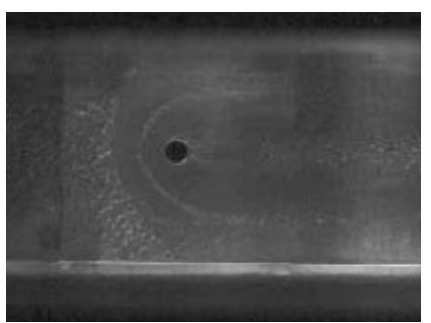

(c) Circular injector

Fig. 4. Results from oil flow visualization. 


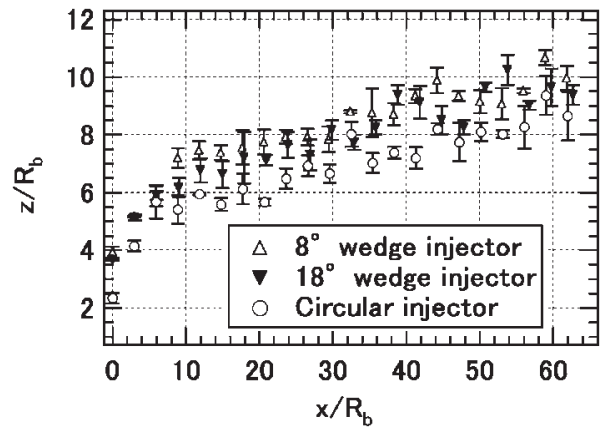

Fig. 5. Penetration height.

(b)) as compared to the circular injector case (Fig. 4(c)). These results show that the wedge shaped injector and especially its sharper vertical angle seem to minimize the boundary layer separation which results in excessive thermal loading.

\subsection{Penetration}

Figure 5 shows the result of the penetration measurement obtained from Schlieren photographs (Fig. 3). The error bar indicated the error mean square of measurements. In Fig. 5, the penetration was defined as the height from the lower wall to the outer edge of the mixing layer in the photographs of Fig. 3. The penetration was normalized by the effective radius $\left(R_{\mathrm{b}}\right)$, as defined by Schetz. ${ }^{17)}$ The effective radius was as follows:

$$
R_{\mathrm{b}}=\sqrt{\frac{\dot{m}_{\mathrm{j}}}{\rho_{\infty} u_{\infty}}}
$$

Where,

$R_{\mathrm{b}}$ : effective radius

$\dot{m}_{\mathrm{j}}$ : mass flow rate of hydrogen jet

$\rho_{\infty}$ : density of freestream

$u_{\infty}$ : velocity of freestream

The mass flow rate of the hydrogen jet was almost the same value in each of the injector cases $\left(R_{\mathrm{b}} \approx 1.69 \mathrm{~mm}\right.$ in the $8^{\circ}$ wedge and circular injector case, $R_{\mathrm{b}} \approx 1.67 \mathrm{~mm}$ in the $18^{\circ}$ wedge injector case) because the nozzle exit area was almost the same. In Fig. 5, in view of the average tendency in the region measured, the penetrations $z / R_{\mathrm{b}}$ in two wedge injector cases were higher than that in the circular injector case. The $8^{\circ}$ wedge injector case was slightly higher than the $18^{\circ}$ wedge injector case. At $x / R_{\mathrm{b}} \approx 0,3,6$, there was not much difference in penetration between the $8^{\circ}$ and $18^{\circ}$ wedge injector cases. As the measurement position went to the $x$ direction, the difference of the penetration was more prominent as indicated above, except with a few measurement positions. This result shows that the $8^{\circ}$ wedge injector was slightly superior to the other two injectors at the point of penetration.

\subsection{Pitot pressure measurements}

Pitot pressure measurements were conducted in the $z$ direction (vertical direction) at $x=29,64$ and $99 \mathrm{~mm}$ (streamwise direction) and $y=0,5$ and $10 \mathrm{~mm}$ (spanwise direction). The measurement positions were normalized by the effective radius, $R_{\mathrm{b}}$. Figure 6 shows the pressure contour

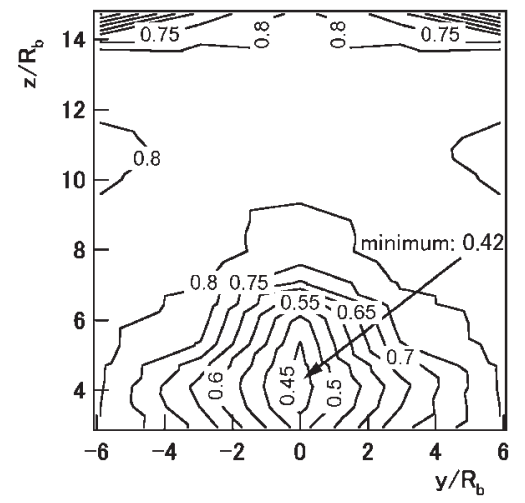

(a) $8^{\circ}$ wedge injector $\left(x=17.1 R_{\mathrm{b}}\right)$

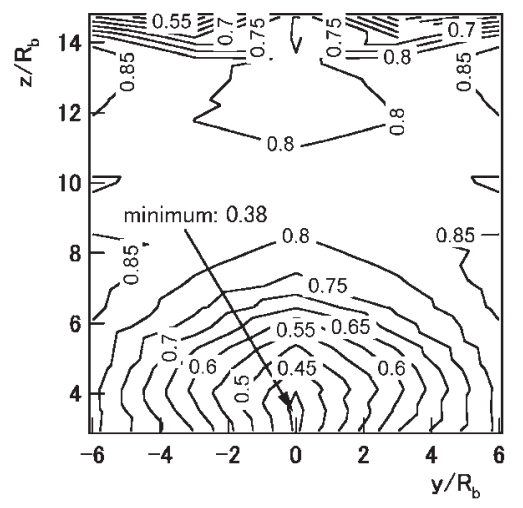

(b) $18^{\circ}$ wedge injector $\left(x=17.3 R_{\mathrm{b}}\right)$

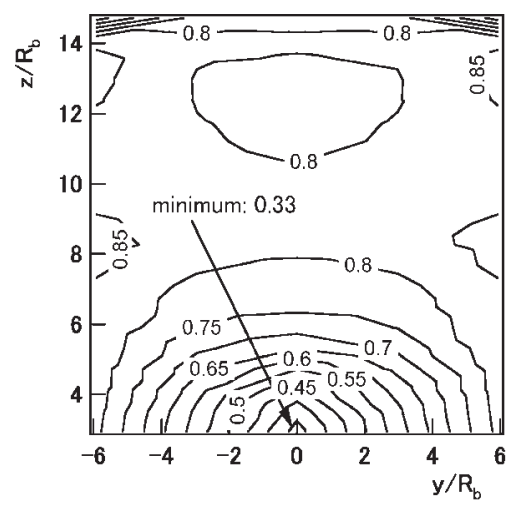

(c) Circular injector $\left(x=17.1 R_{\mathrm{b}}\right)$

Fig. 6. Contour of Pitot pressure (normalized by the total pressure of the wind tunnel).

lines obtained from Pitot pressure measurements at $x \approx 17 R_{\mathrm{b}}$. In Fig. 6 , the contours at $y<0$ were symmetrical to those at $y>0$. These results were normalized by the total pressure of the freestream (atmospheric pressure). It was assumed as follows: the lower the value of pressure was, the greater the total pressure loss. In Figs. 6(a), (b) and (c) the minimum Pitot pressure value in the $8^{\circ}$ wedge injector case was highest among these three injector cases. Specifically, in the $8^{\circ}$ wedge injector, $18^{\circ}$ wedge injector and circular injector cases, the minimum pressure ratios were 0.42 (at $\left.z=4.1 R_{\mathrm{b}}\right), 0.38\left(z=3.6 R_{\mathrm{b}}\right)$ and $0.33\left(z=3.0 R_{\mathrm{b}}\right)$, respectively. The position, which had the minimum value of the Pitot pressure in the $8^{\circ}$ wedge injector case, was far from 
the wall compared with other injector cases. These results indicated that the $8^{\circ}$ wedge injector was superior to the other two injectors at the point of total pressure loss.

\subsection{Supplied electric power}

Figure 7 shows the typical result of supplied electric power to thin wires with constant temperature. If the temperature of the $\mathrm{Ni}$ and $\mathrm{Pt}$ wires were equal, the difference between the supplied electric power to the wires would release heat due to a catalytic reaction, because this reaction occurs only on the Pt wire surface. However, there was a difference between the supplied electric power to the $\mathrm{Ni}$ and $\mathrm{Pt}$ wires at the region out of the mixing layer (more than $z \approx 15 \mathrm{~mm}$ ). This was caused by the contact resistance in the electric circuits shown above. It was calibrated by using the aforementioned method (see section 2.2). Specifically, the averaged difference between the supplied electric power to the $\mathrm{Ni}$ and $\mathrm{Pt}$ wires at a region out of the mixing layer (from $z=20 \mathrm{~mm}$ to $z=25 \mathrm{~mm}$ ) was subtracted from the supplied electric power to the Pt wire (see Fig. 8). The mean temperature may vary from the setting temperature $(836 \pm 5 \mathrm{~K})$ on account of the aforementioned contact resistance. However, even if there were differences between the resistance of $\mathrm{Pt}$ and $\mathrm{Ni}$ wires, namely, the temperatures of these wires, heat release due to catalytic reaction remained invariable. ${ }^{11)}$ Therefore, this calibration (subtracting) was valid.

\subsection{Heat release due to catalytic reaction}

Figure 9 shows the results of heat release due to catalytic reaction. These results were shown after being calibrated by using the method explained above. As for validating this evaluation method, it was proven that the heat release rate

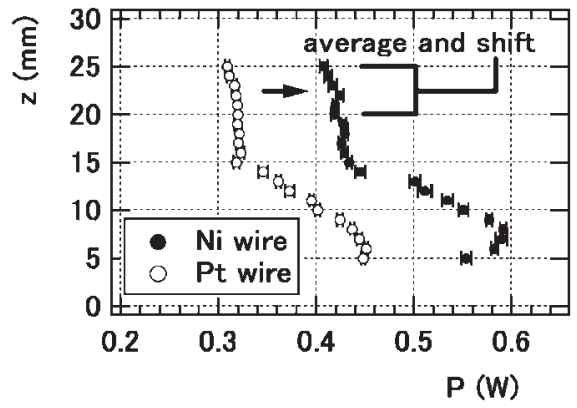

Fig. 7. Example of supplied electric power to thin wires (before shift, $8^{\circ}$ wedge injector, $x=29 \mathrm{~mm}, y=0 \mathrm{~mm}$ ).

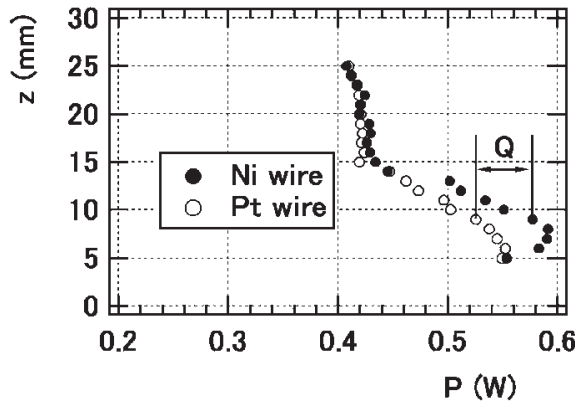

Fig. 8. Example of supplied electric power to thin wires (after shift, $8^{\circ}$ wedge injector, $x=29 \mathrm{~mm}, y=0 \mathrm{~mm}$ ). due to catalytic reaction gave the mass transfer coefficient of the controlling species, which is hydrogen/oxygen in lean/rich mixtures in the previous study. ${ }^{15)}$ However, that evaluation was conducted under uniform density condition. Specifically, the higher the density is the higher the value of the catalytic heat release rate. This was verified in the preliminary experiment. The distribution for hydrogen concentration was not obtained in the present study. However, as the catalytic heat release rate depends on the mass transfer of hydrogen/oxygen as mentioned above, ${ }^{15)}$ it is possible to evaluate the mixing condition by measuring the heat release due to catalytic reaction.

Measurements were conducted in the $z$ direction at $x=$ 29, 64 and $99 \mathrm{~mm}$ (streamwise direction) and $y=0 \mathrm{~mm}$ and $y=5 \mathrm{~mm}$ (spanwise direction). The measurement positions were normalized by the effective radius, $R_{\mathrm{b}}$. In Fig. 9 , some measurement positions varied a little in each injector case (for example, between $y=2.9 R_{\mathrm{b}}$ in the $8^{\circ}$ wedge injector case and $y=3.0 R_{\mathrm{b}}$ in the $18^{\circ}$ and circular injector cases). These were caused because of the difference in effective radius, $R_{\mathrm{b}}$, in each injector case. In Fig. 9(a) of the $8^{\circ}$ wedge injector case, it was found that the mixing layer, in which heat release occurred due to catalytic reaction (standed at $Q>0$ in Fig. 9(a)), penetrated in the $z$ direction as the measurement position went in the $x$ direction. Specifically, at the positions of $y=0,2.9 R_{\mathrm{b}}$, the catalytic reaction occurred in $z<8.2 R_{\mathrm{b}}$ (at $\left.y=0\right), z<9.4 R_{\mathrm{b}} \sim 10.6 R_{\mathrm{b}}\left(y=2.9 R_{\mathrm{b}}\right)$ and $z<9.4 R_{\mathrm{b}} \sim 12.4 R_{\mathrm{b}}\left(y=2.9 R_{\mathrm{b}}\right) ; x=17.1 R_{\mathrm{b}}, 37.7 R_{\mathrm{b}}$, $58.3 R_{\mathrm{b}}$, respectively. In the $18^{\circ}$ wedge injector case (Fig. 9(b)), $Q$ also penetrated in the $z$ direction as the measurement position goes towards the $x$ direction. Specifically, the catalytic reaction occurred in $y=0,3.0 R_{\mathrm{b}}$, and it did $z<$ $8.4 R_{\mathrm{b}}\left(\right.$ at $\left.y=3.0 R_{\mathrm{b}}\right), z<9.0 R_{\mathrm{b}} \sim 10.8 R_{\mathrm{b}}\left(y=3.0 R_{\mathrm{b}}\right)$ and $z<10.2 R_{\mathrm{b}}(y=0) ; x=17.3 R_{\mathrm{b}}, 38.2 R_{\mathrm{b}}, 59.2 R_{\mathrm{b}}$, respectively. The penetration was almost the same in the $18^{\circ}$ wedge injector case as that in the $8^{\circ}$ wedge injector case. On the other hand, in the circular injector case (Fig. 9(c)), the catalytic reaction occurred in $z<6.5 R_{\mathrm{b}} \sim 7.7 R_{\mathrm{b}}$ (at $y=$ $\left.3.0 R_{\mathrm{b}}\right), z<8.3 R_{\mathrm{b}}\left(y=3.0 R_{\mathrm{b}}\right)$ and $z<11.2 R_{\mathrm{b}}(y=0) ; x=$ $17.1 R_{\mathrm{b}}, 37.8 R_{\mathrm{b}}, 58.4 R_{\mathrm{b}}$, respectively. The penetration was lower in the circular injector case than those in the wedge injector cases except with the results in $x \approx 58 R_{\mathrm{b}}$. These results in Fig. 9 were roughly consistent with the result obtained from the Schlieren visualization except with the result of $x \approx 58 R_{\mathrm{b}}$ in the circular injector case (see in Fig. 5). Meanwhile, there were particular differences in $Q$ near the lower wall between the wedge injector cases and the circular injector case. In the wedge injector cases, there was little heat release in $Q$ near the wall. Specifically, in the $8^{\circ}$ wedge injector case, the catalytic reaction did not seem to react at the measurement position near the lower wall, lower than $z=2.9 R_{\mathrm{b}}$ (in all cases) and $z=3.5 R_{\mathrm{b}}$ and $4.1 R_{\mathrm{b}}$ $\left(y=2.9 R_{\mathrm{b}}, x=37.7 R_{\mathrm{b}}\right.$ and $\left.58.3 R_{\mathrm{b}}\right)$. It indicated that there were few hydrogen molecules near the lower wall. Therefore, this result showed that the jet plume developed and separated from the lower wall at both $y=0,2.9 R_{\mathrm{b}}$ of the $8^{\circ}$ wedge injector case. The jet plume of the $18^{\circ}$ wedge in- 


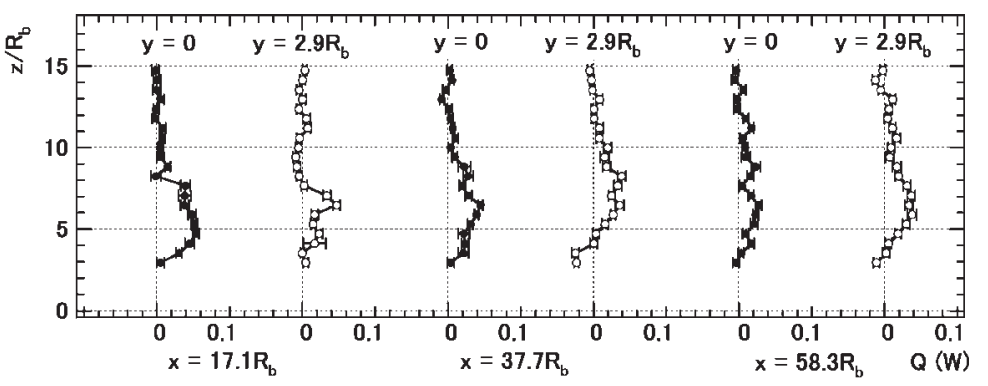

(a) $8^{\circ}$ wedge injector

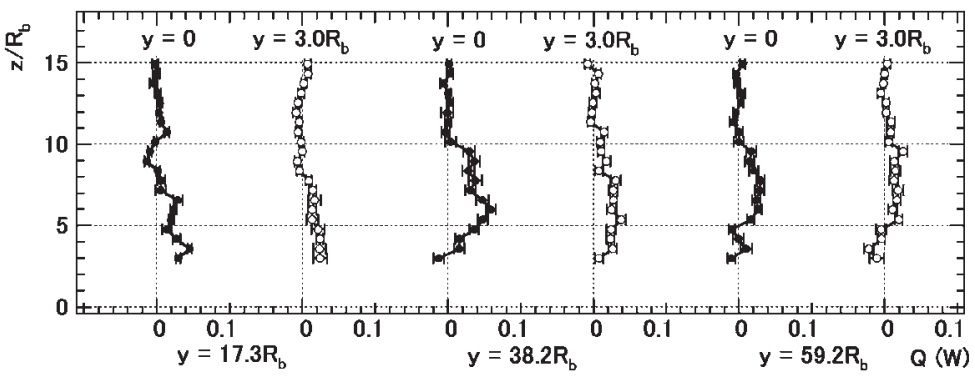

(b) $18^{\circ}$ wedge injector

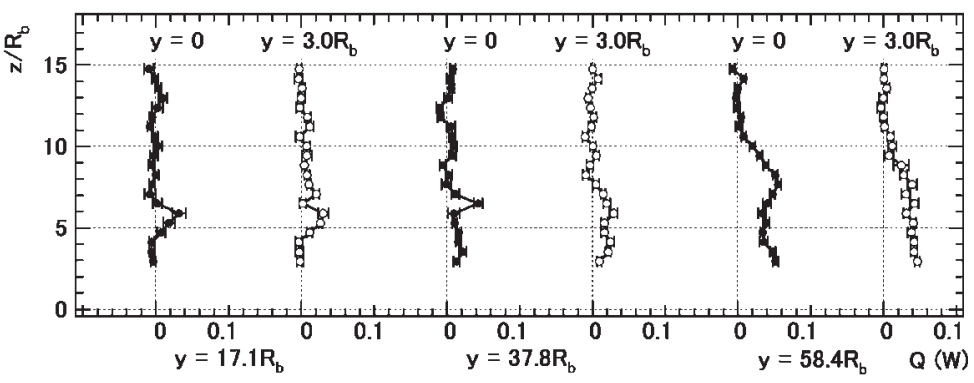

(c) Circular injector

Fig. 9. Heat release due to catalytic reaction.

jector case (Fig. 9(b)) seemed to develop and separate from the lower wall as did the $8^{\circ}$ wedge injector case except when both $y=0,2.9 R_{\mathrm{b}}$ at $x=17.3 R_{\mathrm{b}}$. In these wedge injector cases, cases were hydrogen did not exist near the lower wall. On the other hand, in the circular injector case, there was a heat release $Q$ near the wall except with $x=17.1 R_{\mathrm{b}}$ where the hydrogen concentration seemed to be dense (In other words, the hydrogen did not seem to diffuse into the freestream at $x=17.1 R_{\mathrm{b}}$ ). If the wedge injector is used in the application of the SCRAM jet engine, it may be effective because combustion does not occur near the lower wall, yet does occur far from the wall. Thus, it should be noted that the thermal loading to the wall should be reduced. In addition, the penetration of the $8^{\circ}$ wedge injector case was highest among these injector cases in the present study. This was consistent with the previous result at the point of penetration. ${ }^{7)}$ This indicated that the wedge injector was more effective than the circular injector.

As for validating present studies, in Fig. 9, it was not clear whether the catalytic reaction occurred or not, for example, in $z=9.4 R_{\mathrm{b}} \sim 10.6 R_{\mathrm{b}}$ at the position of $x=37.7 R_{\mathrm{b}}, y=$ $2.9 R_{\mathrm{b}}$ in the $8^{\circ}$ wedge injector case and in $z=9.0 R_{\mathrm{b}} \sim$ $10.8 R_{\mathrm{b}}$ at the position of $x=38.2 R_{\mathrm{b}}, y=3.0 R_{\mathrm{b}}$ in the $18^{\circ}$ wedge injector case. The heat release due to catalytic reaction denoted $Q<0$, for example, in $z=2.9 R_{\mathrm{b}}, 3.5 R_{\mathrm{b}}$ at the position of $x=37.7 R_{\mathrm{b}}, y=2.9 R_{\mathrm{b}}$ in the $8^{\circ}$ wedge injector case. And at $x \approx 58 R_{\mathrm{b}}$ in the circular injector case, there was a difference in penetration between the result from Schlieren visualization and heat release $Q$. These were caused as the measurements in platinum (catalytic reaction) and nickel wire (reference wire) cases were not conducted simultaneously. Therefore, the flow field was not the same every measurement. Furthermore, the $\mathrm{S} / \mathrm{N}$ ratio was considerable because the absolute value of supplied electric power was rather low. In order to increase $\mathrm{S} / \mathrm{N}$ ratio, we have to use the long wire probe to intensify a signal even though it causes to reduce the spatial resolution. Correspondingly, the result obtained at the position of $x=58.3 R_{\mathrm{b}}, y=0$ in the $8^{\circ}$ wedge injector case may imply the same as mentioned above. However, this position was the most downstream among current measurement positions. Therefore, this result may show that heat release due to catalytic reaction decreases as the resulting hydrogen diffuses into the freestream. In addition, in order to verify this evaluation and any uncertainties in detail, the comparison among the present results, CFD and direct sampling among others is needed. 


\section{Concluding Remarks}

In order to ascertain whether a spatial measurement can be conducted by using a catalytic reaction on a thin platinum wire, the measurement was applied to investigate the mixing of a sonic hydrogen jet injected normally through a wedge injector, which had the half-vertical angles of $8^{\circ}$ and $18^{\circ}$, and a cold air supersonic flow (Mach 1.81). The results were compared to those in the circular injector case. It was proven that our proposed technique was indeed effective to measure the mixing condition spatially while also being a practical and easy way to evaluate the mixing condition. However, in order to verify this evaluation in detail, a comparison with other experimental methods is needed. It was also determined that a jet plume in the wedge injector cases was separated from the lower wall.

Next, in order to observe interaction phenomena between the supersonic freestream and the jet, Schlieren photographs were taken and oil flow visualization was conducted. Pitot pressure was also measured. From the results, it was shown that the extent of the separation region around the injector was smaller in the wedge shaped injector cases than of the circular injector case, and that the $8^{\circ}$ wedge shaped injector was superior to the $18^{\circ}$ wedge shaped injector and the circular injector at the point of total pressure loss.

These results indicated that a wedge injector was superior to a circular injector at the point of penetration and mixing for supersonic combustion and wall cooling.

\section{Acknowledgments}

The present research was supported, in part, by JSPS, Grant-inAid for Scientific Research (c), 13650960, 2001-2002. Thanks go to Mr. M. Muramoto and Mr. T. Konishi (Technical Staff) of Muroran Institute of Technology for manufacturing experimental apparatus. Thanks also go to Mr. T. Itagaki and Mr. K. Kitahara (undergraduate student) of Muroran Institute of Technology for their support in the experiments.

\section{References}

1) Scuderi, L. F., Orton, G. F. and Hunt, J. L.: Mach 10 Cruise/Space Access Vehicle Definition, AIAA Paper 98-1584, In AIAA Space Planes and Hypersonic Systems and Technologies Conference, 1998.

2) Sunami, T.: Breakdown Process of Supersonic Streamwise Vortices in Spanwise-Row Configuration, Nagare, J. Jpn. Soc. Fluid Mech., 18 (1999), pp. 136-139 (in Japanese).

3) Wilson, M. P., Bowersox, R. D. W. and Glawe, D. D.: Experimental
Investigation of the Role of Downstream Ramps on a Supersonic Injection Plume, J. Propul. Power, 15 (1999), pp. 432-439.

4) Morita, S., Arai, T., Nagata, H., Hosokawa, H. and Sugiyama, H.: Enhancement of Supersonic Mixing by Backward Facing Step with Ramp Partially (Evaluation of Mixing Condition Using Catalytic Reaction on Constant Temperature Pt Wire), Proceedings of the 38th Conference on Aerospace Propulsion and the 8th Symposium on RAM/SCRAMJETS, 1998, pp. 33-35 (in Japanese).

5) Gruber, M. R., Nejad, A. S., Chen, T. H. and Dutton, J. C.: Mixing and Penetration Studies of Sonic Jets in a Mach 2 Freestream, J. Propul. Power, 11 (1995), pp. 315-323.

6) Arai, T., Hukuzoe, H., Miura, J., Nagata, H. and Hosokawa, H.: Experimental Investigation of Inclined Hydrogen Injection into a Supersonic Flow, AIAA Paper 99-4915, In AIAA Space Planes and Hypersonic Systems and Technologies Conference, 1998.

7) Barber, M. J., Schetz, J. A. and Roe, L. A.: Normal, Sonic Helium Injection through a Wedge-Shaped Orifice into Supersonic Flow, J. Propul. Power, 13 (1997), pp. 257-263.

8) Tomioka, S., Jacobsen, L. S. and Schetz, J. A.: Interaction between a Supersonic Airstream and a Sonic Jet Injected through a DiamondShaped Orifice, AIAA Paper 2000-0088, In 38th Aerospace Sciences Meeting and Exhibit, 2000.

9) Motogi, T., Shiratori, T. and Sakurai, C.: Experimental Research on Helium Gas Injection from a Flat Plate in Supersonic Flow (Estimation on Difference of Injector Shape), Proceedings of the 39th Conference on Aerospace Propulsion, 1999, pp. 371-376 (in Japanese).

10) Arai, T., Endo, A., Nagata, H., Sugiyama, H. and Morita, S.: Catalytic Combustion of Transverse Hydrogen Jet Injection behind a Rear-Facing Step into a Cold Supersonic Flow, Trans. JSME B, 63 (1997), pp. 3318-3324 (in Japanese).

11) Arai, T., Nagata, H., Endo, A., Sugiyama, H., Morita, S. and Hosokawa, H.: Evaluation of Supersonic Turbulent Mixing Using Catalytic Combustion of Constant Temperature Pt Wire, Trans. JSME B, 64 (1998), pp. 793-799 (in Japanese).

12) Arai, T., Morita, S., Nagata, H. and Sugiyama, H.: H2 Concentration Profile in Cold Supersonic Hydrogen-Air Mixing Layer (Evaluation Using Catalytic Reaction on Constant Temperature Pt Wire), AIAA Paper 98-1623, In AIAA 8th International Space Planes and Hypersonic Systems and Technologies Conference, 1998.

13) Arai, T., Kasahara, J., Miura, J., Sakima, F. and Nagata, H.: Hydrogen Concentration of 2-D Supersonic Air-Hydrogen Mixing Layer Using Platinum Catalytic Reaction, Trans. JSME B, 67 (2001), pp. 934939 (in Japanese).

14) Arai, T., Kasahara, J., Sakima, F., Miura, J., Ami, T. and Nagata, H.: Hydrogen Concentration Measurements of Supersonic Hydrogen-Air Shear Layer Using Catalytic Reaction, AIAA Paper 2001-1773, In AIAA 10th International Space Planes and Hypersonic Systems and Technologies Conference, 2001.

15) Nagata, H., Sasaki, M., Arai, T., Totani, T. and Kudo, I.: Evaluation of Mass Transfer Coefficient and Hydrogen Concentration in Supersonic Flow by Using Catalytic Reaction, Proceedings of Combustion Institute, 28 (2000), pp. 713-719.

16) Tada, K., Miyashiro, S., Takayama, K., Kleine, H. and Grönig, H.: Development of Nanosecond Spark Source, J. Jpn. Soc. Aeronaut. Space Sci., 43 (1995), pp. 582-585 (in Japanese).

17) Schetz, J. A.: Interaction Shock Shape for Transverse Injection in Supersonic Flow, J. Spacecraft, 7 (1970), pp. 143-149. 